\title{
The Impact of First Timing of Antibiotics for Community Acquired Pneumonia in Emergency Department
}

\author{
Yiwu Zhou ${ }^{1,2}$, Casey M. Clements ${ }^{3}$, Man $\mathrm{Li}^{4}$, Yanqi He ${ }^{5 *}$, Rong Yao ${ }^{1,2 *}$ \\ ${ }^{1}$ Department of Emergency Medicine, Emergency Medical Laboratory, West China Hospital, Sichuan \\ University, Chengdu, Sichuan 610041, China; 456zyw@163.com (YZ); yaorong@wchscu.cn (RY) \\ 2 Disaster Medical Center, Sichuan University, Chengdu 610041, Sichuan, Chengdu, Sichuan 610041, China \\ ${ }^{3}$ Department of Emergency Medicine, Mayo Clinic, 200 First St SW, Rochester, MN, 55905, USA; \\ Clements.Casey@mayo.edu (CC) \\ ${ }^{4}$ Department of Information Technology, Mayo Clinic, 200 First St SW, Rochester, MN 55905, USA \\ Li.Man@mayo.edu (ML) \\ ${ }^{5}$ Department of Respiratory and Critical Care Medicine, West China Hospital, Sichuan University, Chengdu \\ 610041, China; heyq2004@126.com (YH) \\ * Rong Yao: yaorong@wchscu.cn; Tel: 86018980601415 \\ * Yanqi He: heyq2004@126.com; Tel: 86015390406812
}

\begin{abstract}
Background: The reported associations between time to first antibiotic dose after hospital arrival and short-term mortality have varied in prior studies of CAP. It is unclear the benefit of early antibiotics in all patients given the risks of antibiotic overuse and misdiagnosis; Methods: A PubMed and Google Scholar search was performed to identify articles detailing the epidemiology, prognosis, diagnosis, and preliminary management of CAP; Results: In sepsis, antibiotics should not be delayed, and should be administered as soon as possible after recognition. For moderate or severe CAP patients without sepsis, antibiotics should be administered as soon as the diagnosis of CAP is highly likely. For stable, non-critically ill patients with CAP, the timing of antibiotics is not as clear and available evidence does not recommend strict requirements. Antibiotic timing - both rapid and delayed could be used as indicators of quality care in differing clinical scenarios; Results: The dogma of starting antibiotics quickly, within a rigid timeframe of expectations and guidelines has not improved outcomes in pneumonia patients, and has led to an increase in antibiotic treatment in uninfected patients. Severity of illness is the key factor associated with poor outcomes and should more significantly guide the timing of antibiotic initiation.
\end{abstract}

Keywords: Pneumonia; Timing; Antibiotics; Outcome

\section{Introduction}

Community-acquired pneumonia is a commonly encountered respiratory infection in the emergency department that is a leading cause of hospitalization, morbidity, and mortality [1-4]. CAP is defined as a syndrome in which acute infection of the lungs develops in persons without recent health care exposure[5]. CAP particularly impacts the old or the very young, with an annual incidence of 9.2 to 33 per 1,000 persons[2, 6]. Each year in the United States, community-acquired pneumonia is responsible for approximately 600,000 hospital admissions and costs $\$ 10.6$ billion[7]. CAP can be a severe infection and $5-7 \%$ of patients admitted with CAP die in the hospital in the United States and Canada. For older patients with comorbidities or immunocompromised the mortality reaches $28 \%$ in admitted patients[8].

A short time to first antibiotic dose (TFAD) has attracted attention as a popular and intuitive 
target for CAP in the ED, although this is based on retrospective database studies[9]. The reported associations between TFAD after hospital arrival and short-term mortality have varied in prior studies of CAP, and TFAD after hospital arrival remains uncertain. Observational data suggest lower short-term mortality when antibiotic therapy is administered within four to eight hours of hospital arrival in patients with moderate or severe pneumonia[7]. This remains controversial however, and other studies have found that mortality may not improve, and may even increase with a short TFAD[10, 11], which may be caused by the urgent medical attention with severe CAP patients rather than a causal effect. It is unclear the benefit of early antibiotics in all patients given the risks of antibiotic overuse and misdiagnosis[12].

Attention to TFAD may also result in reduced attention to and investment in the needs of other time-sensitive patients in resource-limited settings like EDs. Previous efforts to require and report on TFAD in CAP were challenged for several reasons, including antibiotic abuse, overuse of antibiotics, misdiagnosis. So it has been proposed that TFAD in CAP should be used as a marker of quality, optimal care rather than predicting outcomes as it does with sepsis[10].

\section{METHODS}

A PubMed and Google Scholar search was performed to identify articles detailing the epidemiology, prognosis, diagnosis, and preliminary management of CAP. The following key words were used: community acquired pneumonia; timing; antibiotics; outcome. These results were narrowed to include English-language articles and, of those results, authors reviewed articles to identify those relevant to the emergency department (ED) management of CAP. Excluded studies include those that did not introduce the duration of initial antibiotic use.

\section{Results}

A total of 16 studies that meet the requirements were included in the analysis (Table 1).

Table 1. Description of Studies Evaluating Time to Initiate Antibiotic Therapy for Patients Hospitalized With Community-Acquired Pneumonia

\begin{tabular}{|c|c|c|c|c|c|c|c|}
\hline Source & $\begin{array}{l}\text { Study } \\
\text { design }\end{array}$ & $\begin{array}{l}\text { Patient of } \\
\text { data } \\
\text { collection }\end{array}$ & $\begin{array}{l}\text { NO. of } \\
\text { Study } \\
\text { Sites }\end{array}$ & $\begin{array}{l}\text { NO. of } \\
\text { Patients }\end{array}$ & Ages & $\begin{array}{l}\text { Mortality } \\
\text { definition }\end{array}$ & $\begin{array}{l}\text { Evidence } \\
\text { quality }^{\mathrm{a}}\end{array}$ \\
\hline \multicolumn{8}{|c|}{ Threshold Evaluated within $1 \mathrm{~h}$} \\
\hline Jason et al ${ }^{29}, 2016$ & $\begin{array}{l}\text { Systematic } \\
\text { review }\end{array}$ & $1981-2016$ & $\begin{array}{l}\text { Data not } \\
\text { available }\end{array}$ & 11,017 & $\begin{array}{l}\text { Data not } \\
\text { available }\end{array}$ & $\begin{array}{l}\text { In-hospital } \\
\text { or 28-day }\end{array}$ & Moderate \\
\hline Threshold Evaluatec & within $2 \mathrm{~h}$ & & & & & & \\
\hline $\begin{array}{l}\text { Brett A. et al27, } \\
2017\end{array}$ & Retrospective & 2008-2016 & 1 & 406 & $\begin{array}{l}61.8 \\
\text { (mean) }\end{array}$ & In-hospital & Low \\
\hline \multicolumn{8}{|c|}{ Threshold Evaluated within $3 \mathrm{~h}$} \\
\hline $\begin{array}{l}\text { Trad MA et } \mathrm{al}^{26} \text {, } \\
2017\end{array}$ & Retrospective & $2012-2013$ & 1 & 312 & $\begin{array}{l}71 \\
\text { (mean) }\end{array}$ & $\begin{array}{l}\text { In-hospital } \\
\text { 30-day } \\
60 \text {-day }\end{array}$ & Low \\
\hline $\begin{array}{l}\text { Gattarello et } \text { al }^{28} \text {, } \\
2014\end{array}$ & Prospective & $2008-2013$ & 29 & 160 & $\begin{array}{l}58 \\
\text { (mean) }\end{array}$ & ICU & Moderate \\
\hline Threshold Evaluatec & within $4 \mathrm{~h}$ & & & & & & \\
\hline
\end{tabular}




\begin{tabular}{|c|c|c|c|c|c|c|c|}
\hline Houck et al ${ }^{32}, 2004$ & Retrospective & 1998-1999 & 3463 & 13771 & $\begin{array}{l}\text { Data not } \\
\text { available }\end{array}$ & 30-day & Low \\
\hline $\begin{array}{l}\text { Waterer et } \mathrm{al}^{34} \text {, } \\
2006\end{array}$ & Prospective & 1998-2001 & 1 & 451 & $\begin{array}{l}58 \\
\text { (mean) }\end{array}$ & In-hospital & Low \\
\hline $\begin{array}{l}\text { Kenneth et } \mathrm{al}^{30} \text {, } \\
2008\end{array}$ & $\begin{array}{l}\text { Systematic } \\
\text { review }\end{array}$ & $1966-2006$ & $\begin{array}{l}\text { Data not } \\
\text { available }\end{array}$ & 22387 & $\begin{array}{l}\text { Data not } \\
\text { available }\end{array}$ & 30-day & Low \\
\hline Lee et $\mathrm{al}^{35}, 2011$ & Prospective & 2001 & 32 & 2076 & $\begin{array}{l}74 \\
\text { (median) }\end{array}$ & 30-day & Low \\
\hline $\begin{array}{l}\text { Simonetti et } \mathrm{al}^{33} \text {, } \\
2012\end{array}$ & Prospective & 2001-2009 & 1 & 1274 & $\begin{array}{l}\text { Data not } \\
\text { available }\end{array}$ & 30-day & Low \\
\hline $\begin{array}{l}\text { Chamira et } \mathrm{al}^{31} \text {, } \\
2015\end{array}$ & Prospective & 2009-2013 & 2 & 371 & $\begin{array}{l}76 \\
\text { (mean) }\end{array}$ & $\begin{array}{l}\text { In-hospital } \\
\text { 30-day } \\
\text { 90-day }\end{array}$ & Low \\
\hline \multicolumn{8}{|c|}{ Threshold Evaluated within $6 \mathrm{~h}$} \\
\hline $\begin{array}{l}\text { Battleman et } \mathrm{al}^{39} \text {, } \\
2002\end{array}$ & Retrospective & 1998 & 7 & 609 & $\begin{array}{l}67 \\
\text { (mean) }\end{array}$ & $\begin{array}{l}\text { Data not } \\
\text { available }\end{array}$ & Low \\
\hline Lee et $\mathrm{al}^{42}, 2014$ & Retrospective & 2006-2010 & 4740 & $\begin{array}{ll}1 & 170 \\
022 & \end{array}$ & $\begin{array}{l}80 \\
\text { (mean) }\end{array}$ & 30-day & Low \\
\hline \multicolumn{8}{|c|}{ Threshold Evaluated within $8 \mathrm{~h}$} \\
\hline $\begin{array}{l}\text { Meehan et } \mathrm{al}^{14} \text {, } \\
1997\end{array}$ & Retrospective & 1994-1995 & 3555 & 14069 & $\begin{array}{l}79 \\
\text { (mean) }\end{array}$ & 30-day & Low \\
\hline Dedier et $\mathrm{al}^{40}, 2001$ & Retrospective & 1997-1998 & 38 & 1062 & $\begin{array}{l}64 \\
\text { (median) }\end{array}$ & In-hospital & Low \\
\hline Arnold et al ${ }^{41}, 2007$ & Retrospective & 2001-2006 & 39 & 2878 & $\begin{array}{l}65 \\
\text { (mean) }\end{array}$ & In-hospital & Low \\
\hline $\begin{array}{l}\text { Simonetti et } \mathrm{al}^{33} \text {, } \\
2012\end{array}$ & Prospective & 2001-2009 & 1 & 1274 & $\begin{array}{l}\text { Data not } \\
\text { available }\end{array}$ & 30-day & Low \\
\hline
\end{tabular}

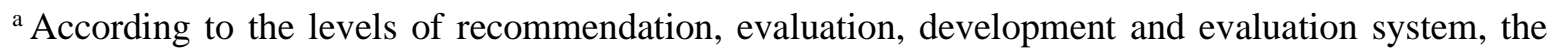
two authors of this study classified them as high, medium, low or very low respectively.

\section{Discussion}

The impact of timing of antibiotics on outcomes in CAP

Clearly, patients with bacterial pneumonia warrant treatment. However, the timing of that treatment remains controversial and we are forced to rely on current guidelines based on relatively poor evidence. Guidelines recommend treating patients with antibiotics as soon as the diagnosis of CAP is confirmed. Ideally, these should be given before they leave the initial assessment area (emergency department or acute medical unit). It should be noted that TFAD of CAP patients varies in different countries and regions. In addition, any discussion on treatment times must take into account disease severity. Antibiotics should be administered within the first hour of recognition of CAP with sepsis. But TFAD is controversial for moderate or severe CAP without sepsis. Early studies demonstrated some survival benefit in pneumonia patients related to early appropriate antimicrobial therapy[13-15]. Indeed, most observational data suggest lower short-term mortality 
when TFAD within four to eight hours of hospital arrival in patients with moderate or severe pneumonia. But in a randomized controlled trial of patients hospitalized for moderate-severe CAP, a shorter time to TFAD was not associated with a favorable outcome[16]. This prospective study has also raised concerns about the early administration of antibiotics in CAP patients. In patients with more mild disease, there is not clear evidence to guide TFAD.

Early administration of antibiotics for CAP

It is widely accepted and biologically plausible that administering antibiotics as early as possible to CAP patients with sepsis or sepsis shock should improve their outcomes[17]. The Surviving Sepsis Campaign recommends administering antibiotics within the first hour of recognition of sepsis and septic shock. Indeed, early studies have shown that this can improve the prognosis of CAP with sepsis[18-22]. Early TFAD has motivated international guidelines and quality benchmarks in sepsis care[23, 24]. In a large multicenter study of patients with sepsis in the emergency department, hourly delays in antibiotic administration were associated with increased hospital mortality rate even among patients who received antibiotics therapy within 6 hours[25]. Although some studies had questioned this point view, most studies still support the administering antibiotics quickly for sepsis patients.

Confirming the diagnosis and severity of CAP takes some time, and in the absence of sepsis antibiotic treatment may be delayed. In most studies the mean time to first antibiotic dose in CAP patients is approximately 3 hours[26, 27]. A matched case-control, prospective study of two cohorts of patients in Europe demonstrated early antibiotic administering within $3 \mathrm{~h}$ was associated with improved survival in severe pneumococcal CAP[28]. The mortality due to non-pneumococcal severe CAP decreased between the two cohorts, and early antibiotic administration as well as the use of combined antibiotic therapy were associated with lower hospital mortality. These findings are consistent with the conclusions from a previous study carried out in patients with pneumococcal severe CAP from the same database[28, 29].

Guidelines and a four hours standard

In 2004, the Joint Commission on Accreditation of Hospital Organizations (JCAHO) mandated the time to first antibiotics for patients with a "working diagnosis" of pneumonia to be within 4 hours of ED arrival. The 2009 and 2015 British Thoracic Society (BTS) Guideline for CAP states that the objective for any service should be to confirm a diagnosis of pneumonia with chest radiography and first antibiotic be administered for the majority of patients with CAP within $4 \mathrm{~h}$ of presentation to hospital. However, the evidence in support of this comes from observational studies that are inconsistent and that suggest the association between early antibiotics administering and short term-mortality diminishes or disappears in studies of higher methodological quality. Although the time to first antibiotics administered in the ED with confirmed CAP is a valuable clinical objective, an inflated sense of priority of the 4-hour time frame or antibiotic administration before confirmation of the CAP diagnosis is unreasonable by the clinical evidence[30, 31]. Since these guidelines have been released, there have been many studies which adopt 4-hour time as the cut-off time to compare outcomes. A subsequent study of 13,771 older patients ( $\geq 65$ years) that used a similar design and severity adjustment method also reported that antibiotic administering within 4 hours or less of ED arrival was associated with 15\% reduction in 30-day mortality[32]. Conversely, a 
large study by Rodrigo et. al., showed that administering antibiotics within 4 hours did not translate into a benefit in short-term mortality[31]. Other smallest studies found no significant associations between the time to first antibiotic administering and short-term mortality in adults of all ages[33-35]. Recently a randomized controlled trial was reported that found in patients hospitalized for moderate and severe CAP, a shorter time to first antibiotic administration was not associated with a favorable outcome[16].

Administering antibiotics within six to eight hours

In September 2007, The Joint Commission specification manual was revised to recommend TAFD for CAP to be within 6 hours. Citing the Infectious Disease Society of America/American Thoracic Society guideline revision in 2007, the manual replaces the initial 4-hour time mandate (PN-5b) with a 6-hour mandate (PN-5c)[36]. However, a systematic review indicates that the evidence supporting a 6-hour or 8-hour mandate is no stronger than that in favor of the initial 4-hour mandate[7]. A recent retrospective study of $1,170,022$ elderly patients (( $\geq 65$ years) demonstrated that administration of a first antibiotic within 6 hours of hospital arrival resulted in a $5 \%$ relative reduction in 30-day mortality, adjusting for the patient's demographic characteristics and comorbidity[37]. In 2012, JCAHO again altered their recommendation to focus on antibiotic selection within the first 24 hours of hospitalization and has veered away from recommending TFAD. Six hours remains a widely held expectation in general[5, 38-42].

Antibiotics are administered within 8 hours of hospital arrival for most CAP patients. Of course, for some patients the treatment will be delayed due to unclear diagnosis or other reasons. A cohort study by Laura Fuchs Bahlis reported the mean time from patient arrival at the emergency room to initiation of antibiotic therapy was $10.4 \pm 7.7$ hour in a (which country/kind of ED)[43]. A retrospective study of 14,069 older patients ( $\geq 65$ years) reported that first antibiotics were administered within 8 hours (vs $>8$ hours) of hospital arrival was associated with a relative reduction of $15 \%$ mortality at 30 days, adjusting for illness severity with the pneumonia severity index[14]. Another retrospective cohort study of 2,878 patients proved that administering antibiotic within 8 hours of hospital arrival was also associated with a relative reduction in hospital mortality of $43 \%$ [44]. Of course, some recent studies have not specified a specific point in first antibiotics time, but rather proposed a relatively loose time period. A recent systematic review of four large observational studies concluded that administering antibiotics for CAP within 4-8 hours of hospital arrival resulted in a relative $5-43 \%$ reduction in mortality, even in non-ICU patients[7]. Administering antibiotics such as beta-lactam and macrolide, or a fluoroquinolone within $4-8 \mathrm{~h}$ of ED arrival was associated with lower adjusted short-term mortality, but the conclusion only comes from low-quality, observational studies. Large scale, non-commercial, randomized controled trials are needed to determine the optimal time to first antibiotic administering for CAP [5].

Administering antibiotics for stable CAP patients

The time from ED visit of a stable, non-critical patient with CAP to the administering of first antibiotics dose is a managerially determined characteristic[7, 8]. Patients with this type of CAP typically have been sick for several days prior to their visit, and timing may be influenced by factors that are not related to the biological time scale of the infection. So rushing to antibioitics quickly may not be as critical, and diagnosis could be more reliably confirmed by adequate testing. 
Factors affecting antibiotic timing

Chest CT imaging enhances the diagnosis rate of pneumonia, with sensitivity that approaches $100 \%[45,46]$. Chest CT image is often warranted in patients with respiratory symptoms and signs of sepsis or shock, but negative chest radiograph. The time to complete the chest radiograph and CT image greatly influences the time of first antibiotic administration. The time to image acquisition and interpretation can vary greatly in different practice environments based on available resources. Lung ultrasound had a high sensitivity and specificity for the diagnosis of pneumonia in adults[47-49]. It has good discrimination even in patients with acute dyspnea. Lung ultrasound can be performed in less than 13 minutes in ED and substantially shorter than the timeframe required for a CXR or chest CT scan.

There is no longer a time for Medicare \& Medicaid Services (CMS) quality metric regarding to first antibiotics administering, but a widely accepted target is within four to eight hours of hospital arrival[38]. This recommendation is largely based on the ideal of a stable patient without critical illness. CAP patients who exhibit signs of sepsis should been administered antibiotics as soon as possible and recent guidelines have recommended giving them within 1 hour[17]. Moderate to severe has to have a lower threshold for administration than mild disease.

Often, the timing of ED presentation for CAP patients is influenced by factors having little to do with the biological time scale of the infection itself. Since the timing of antibiotic initiations is variable based on disease severity, it is reasonable that emergency physicians routinely use a structured approach or clinical decision rule to risk stratify patients with CAP before starting antibiotics. Several guidelines and recommendations exist for risk stratification of CAP including: pneumonia severity index (PSI), CURB-65, and several national and international societies' guidelines have been proposed to prognose CAP patients' course of illness and have been proposed to help guide disposition of the patient[50]. Bot PSI and CURB-65 use vital signs and lab data to calculate a score that correlates with clinical outcomes. PSI is more specific with five classifications and requires several lab measurements. CURB-65 on the other hand only requires five data points and is simple to use. Both PSI and CURB65 aim to help identify patients that may be safely treatable as an outpatient[51]. IDSA in cooperation with the American Thoracic Society (ATS), published criteria in 2007 that also aim to help identify level of care determination for inpatients, and provide separate recommendations for outpatients including comorbidities. The British Thoracic Society (BTS) guidelines use the CURB 65 score in conjunction with clinical judgment. A Dutch guideline is a mixture of IDSA/ATS and BTS guidelines, as it is recommended to use any of the three classification systems (PSI, CURB 65, or pragmatic classification) rather than special recommendations. However, few studies have used these rules to guide the time to first antibiotics administering in ED. In fact, clinicians always determine the time of first antibiotic administering based on the severity of the patient's condition. Those who have a more severe infection should be administered antibiotics more quickly.

Serum inflammatory markers (such as procalcitonin, c-reactive proteins, etc.) are being proposed as adjuncts or alternatives to clinical severity scores, which may affect TFAD in CAP[52]. It remains unclear if serum inflammatory markers are useful in the ED. CRP may play a role in determining clinical stability, but its kinetics lag behind clinical presentation which makes it an unreliable indicator for CAP severity at ED presentation[53]. In addition, CRP is not sensitive and 
does not rule out a complicated course of illness, limiting its use in guiding early treatment. We do not recommend using CRP within the decision start antibiotics[54]. Early studies using procalcitonin (PCT) to help direct antibiotic use in CAP were promising [55]. The thinking was that PCT could help separate out viral pneumonia, COPD exacerbation, and pulmonary edema from bacterial pneumonia that requires antibiotics if the diagnosis of CAP was unclear in patients without critical illness. These early studies found that using PCT to guide antibiotic treatment, helped reduce treatment duration, cost and adverse effects and helped in making decisions to step down to oral antibiotics[56-58]. However, the ProACT trial, a multicenter randomized trial to evaluate the use of PCT in guiding antibiotic initiation did not find PCT adequately effective. This may be because other acute illness conditions, including heart failure can lead to increases in PCT[59]. Additionally, antibiotic administration in admitted patients is associated with decreasing PCT levels even in the absence of likely bacterial infection (e.g. bronchitis, COPD exacerbation). Other biomarkers, such as IL-6 and pro-adrenomedullin may have prognostic value but these tests have not been studied extensively in many clinical settings and remain rare and expensive. Elevated blood urea nitrogen (BUN) and glucose, as well as low levels of sodium, while not biomarkers in the traditional sense, are associated with worse outcomes and therefore more severe disease. These are incorporated into several of the risk stratification scoring systems and should not be ignored in the clinical evaluation of CAP patients. Currently however, these are rarely used to guide the initiation of antibiotics in $\mathrm{ED}[12]$.

ED overcrowding affects almost all aspects of care delivery in an ED, including antibiotic initiation, and should not be ignored as a major contributor to delaying or rushing in diagnosis, ordering, and administration of antibiotics[60]. This may only get worse without systemic changes since data suggest that recent growth in ED presentations worldwide may be unsustainable while trying to deliver the highest quality of care[61,62]. CAP presentaitons and admissions are common and are not exempt from this trend[31]. Indeed, available evidence shows that overcrowding is associated with delays and poor outcomes in adults with CAP [63]. Overcrowding could also affect aggressive ED providers to have a lower threshold to initiate treatment of pneumonia, even without confirmation of the diagnosis, since overcrowding prevents attention to detail given competing clinical responsibilities. However, studies are lacking and would be difficult to conduct given the adverse effects of inappropriate antibiotic treatment are long term and can affect populations as well as individuals.

\section{Disadvantages of early antibiotic therapy for CAP}

A retrospective study of adult CAP patients showed that the CMS guideline reduction in the expected time to first antibiotic administration from 8 to 4 hours was associated with a reduction in diagnostic accuracy by ED physicians, while failing to significantly reduce the actual TFAD given to CAP patients[64]. In another study, in order to achieve an increase in the number of patients with time to first antibiotic administering $<4 \mathrm{~h}$, an additional $17 \%$ of patients were unnecessarily administered antibiotics[65]. Observational studies also find that implementation of the $<4$ hours expection for antibiotics in CAP did not improve all-cause mortality but was associated with an increase in unnecessary antibiotic treatment[11]. A retrospective study reported that the pressure to comply with the $4 \mathrm{~h}$ antibiotics administering principle in ED and a 'better safe than sorry' approach tended to "overtreat" adults with intravenous antibiotics regardless of CAP severity[66]. 
This is problematic since the effect of unnecessary antibiotic treatment, such as Clostridium Difficile infection, drug reactions and allergies, physiologic detriment such as dehydration in the setting of diarrhea, and antibiotic resistance are difficult to measure leading to an underappreciation of the incidence of adverse outcomes. This makes a risk/benefit decision difficult since the harm is likely underappreciated. Improving our rigor in deciding to start antibiotics for low severity CAP is increasingly important in this setting and is consistent with national multidisciplinary goals such as the UK's Department of Health Antimicrobial Resistance Strategy[33]. In this as well, our assessment is that attention should be directed to starting early appropriate antibiotic treatment first in sepsis, regardless of the source of infection, then for patients with likely CAP with severe features or comorbidities, and that guidelines focusing on low severity CAP are of limited value and past experiences have shown detrimental effects to implementing such rigorous expectations.

\section{Conclusions}

he dogma of starting antibiotics quickly, within a rigid timeframe of expectations and guidelines has not improved outcomes in pneumonia patients, and has led to an increase in antibiotic treatment in uninfected patients. Severity of illness is the key factor associated with poor outcomes and should more significantly guide the timing of antibiotic initiation. Unlike many organizations' guidelines and recommendations, we suggest a change in thinking around antibiosis for pneumonia where rapid administration and delayed prescribing can both be thought of as quality care within differing clinical situations. This could be operationalized around systems that focus on clinical assessment, risk stratification, clarity of imaging studies, and incorporation of ancillary data such as lab testing and patient factors/comorbidities in order to guide the rapidity of treatment.

\section{Author Contributions:}

Conceptualization, Yiwu Zhou and Casey M. Clements; methodology, Yanqi He; software, Man Li; validation, Yiwu Zhou, Casey M. Clements and Rong Yao; formal analysis, Yanqi He; investigation, Man Li; data curation, Yiwu Zhou; writing - original draft preparation, Yiwu Zhou and Casey; writing - review and editing, Casey M. Clements; visualization, X.X.; supervision, Yanqi He; project administration, Rong Yao; funding acquisition, Rong Yao. All authors have read and agreed to the published version of the manuscript.

\section{Funding:}

This research was funded by the Emergency Response Project for New Coronavirus of Science and Technology Department of Sichuan Provincial (No. 2020YFS0009, 2020YFS0005), Special Funds for COVID-19 Prevention and Control of West China Hospital of Sichuan University (HX-2019-nCoV-068), and Science and Technology Benefit People Project of Chengdu Municipality (2016-HM02-00099-SF).

\section{Conflicts of Interest:}

The authors have no conflict of interest to declare.

\section{References}

1. Capelastegui A, Espana PP, Quintana JM, et al. Improvement of process-of-care and outcomes after implementing a guideline for the management of community-acquired pneumonia: A controlled before-and-after design study. Clin Infect Dis 2004; 39:955-63.

2. Gattarello S, Borgatta B, Sole-Violan J, et al. Decrease in mortality in severe community-acquired 
pneumococcal pneumonia: impact of improving antibiotic strategies (2000-2013). Chest 2014; 146:22-31.

3. Rider AC, Frazee BW. Community-Acquired Pneumonia. Emerg Med Clin North Am 2018; 36:665-83.

4. Quan TP, Fawcett NJ, Wrightson JM, et al. Increasing burden of community-acquired pneumonia leading to hospitalisation, 1998-2014. Thorax 2016; 71:535-42.

5. Musher DM, Thorner AR. Community-acquired pneumonia. N Engl J Med 2014; 371:1619-28.

6. Cavallazzi R, Wiemken T, Arnold FW, et al. Outcomes in patients with community-acquired pneumonia admitted to the intensive care unit. Respir Med 2015; 109:743-50.

7. Lee JS, Giesler DL, Gellad WF, Fine MJ. Antibiotic Therapy for Adults Hospitalized With Community-Acquired Pneumonia: A Systematic Review. JAMA 2016; 315:593-602.

8. Long B, Long D, Koyfman A. Emergency Medicine Evaluation of Community-Acquired Pneumonia: History, Examination, Imaging and Laboratory Assessment, and Risk Scores. J Emerg Med 2017; 53:642-52.

9. Rhodes A, Evans LE, Alhazzani W, et al. Surviving Sepsis Campaign: International Guidelines for Management of Sepsis and Septic Shock: 2016. Intens Care Med 2017; 43:304-77.

10. Bordon J, Aliberti S, Duvvuri P, et al. Early administration of the first antimicrobials should be considered a marker of optimal care of patients with community-acquired pneumonia rather than a predictor of outcomes. Int J Infect Dis 2013; 17:E293-E8.

11. Yahav D, Leibovici L, Goldberg E, Bishara J, Paul M. Time to first antibiotic dose for patients hospitalised with community-acquired pneumonia. Int J Antimicrob Ag 2013; 41:410-3.

12. Hadfield J, Bennett L. Determining best outcomes from community-acquired pneumonia and how to achieve them. Respirology 2018; 23:138-47.

13. Houck PM, Bratzler DW, Nsa W, Ma A, Bartlett JG. Timing of antibiotic administration and outcomes for medicare patients hospitalized with community-acquired pneumonia. Arch Intern Med 2004; 164:637-44.

14. Meehan TP, Fine MJ, Krumholz HM, et al. Quality of care, process, and outcomes in elderly patients with pneumonia. Jama-J Am Med Assoc 1997; 278:2080-4.

15. Pines JM. Timing of antibiotics for acute, severe infections. Emerg Med Clin N Am 2008; 26:245-+.

16. Marti C, John G, Genne D, et al. Time to antibiotics administration and outcome in community-acquired pneumonia: Secondary analysis of a randomized controlled trial. Eur J Intern Med 2017; 43:58-61.

17. Dellinger RP, Levy MM, Rhodes A. Surviving Sepsis Campaign: International Guidelines for Management of Severe Sepsis and Septic Shock: 2012 (vol 41, pg 580, 2013). Crit Care Med 2014; 42:E88-E.

18. Gattarello S, Lagunes L, Vidaur L, et al. Improvement of antibiotic therapy and ICU survival in severe non-pneumococcal community-acquired pneumonia: a matched case-control study. Crit Care 2015; 19.

19. Kumar A, Roberts D, Wood KE. Duration of hypotension before initiation of effective antimicrobial therapy is the critical determinant of survival in human septic shock. Ann Intern Med 2007; 147:413-

20. Sterling SA, Miller WR, Pryor J, Puskarich MA, Jones AE. The Impact of Timing of Antibiotics on Outcomes in Severe Sepsis and Septic Shock: A Systematic Review and Meta-Analysis. Crit Care Med 2015; 43:1907-15.

21. Sivapalan P, Jensen JUS. Timing of Therapy in Sepsis: Are Early Antibiotics Important for Prognosis? Crit Care Med 2015; 43:2030-+.

22. Dellinger RP, Levy MM, Rhodes A, et al. Surviving Sepsis Campaign: International Guidelines for Management of Severe Sepsis and Septic Shock: 2012. Crit Care Med 2013; 41:580-637.

23. Seymour CW, Rosengart MR. Septic Shock Advances in Diagnosis and Treatment. Jama-J Am Med Assoc $2015 ; 314: 708-17$.

24. Angus DC, van der Poll T. Severe Sepsis and Septic Shock REPLY. New Engl J Med 2013; 369:2063-.

25. Liu VX, Fielding-Singh V, Iwashyna TJ, Bhattacharya J, Escobar GJ. The Timing of Early Antibiotics and 
Hospital Mortality in Sepsis: Playing Devil's Advocate Reply. Am J Resp Crit Care 2017; 196:935-6.

26. Trad MA, Baisch A. Management of community-acquired pneumonia in an Australian regional hospital. Aust J Rural Health 2017; 25:120-4.

27. Faine BA, Mohr N, Dietrich J, Meadow L, Harland KK, Chrischilles E. Antimicrobial Therapy for Pneumonia in the Emergency Department: The Impact of Clinical Pharmacists on Appropriateness. West J Emerg Med 2017; 18:856-63.

28. Gattarello S, Borgatta B, Sole-Violan J, et al. Decrease in Mortality in Severe Community-Acquired Pneumococcal Pneumonia Impact of Improving Antibiotic Strategies (2000-2013). Chest 2014; 146:22-31.

29. Phua J, Dean NC, Guo Q, Sen Kuan W, Lim HF, Lim TK. Severe community-acquired pneumonia: timely management measures in the first 24 hours. Crit Care 2016; 20.

30. Yu KT, Wyer PC. Evidence-based emergency medicine/critically appraised topic. Evidence behind the 4-hour rule for initiation of antibiotic therapy in community-acquired pneumonia. Ann Emerg Med 2008; 51:651-62, 62 e1-2.

31. Rodrigo C, McKeever TM, Woodhead M, Welham S, Lim WS, British Thoracic S. Admission via the emergency department in relation to mortality of adults hospitalised with community-acquired pneumonia: an analysis of the British Thoracic Society national community-acquired pneumonia audit. Emerg Med J 2015; 32:55-9.

32. Houck PM, Bratzler DW, Nsa W, Ma A, Bartlett JG. Timing of antibiotic administration and outcomes for Medicare patients hospitalized with community-acquired pneumonia. Arch Intern Med 2004; 164:637-44.

33. Simonetti A, Viasus D, Garcia-Vidal C, et al. Timing of antibiotic administration and outcomes of hospitalized patients with community-acquired and healthcare-associated pneumonia. Clin Microbiol Infect 2012; 18:1149-55.

34. Waterer GW, Kessler LA, Wunderink RG. Delayed administration of antibiotics and atypical presentation in community-acquired pneumonia. Chest 2006; 130:11-5.

35. Lee JS, Primack BA, Mor MK, et al. Processes of Care and Outcomes for Community-Acquired Pneumonia. Am J Med 2011; 124.

36. Mandell LA, Wunderink RG, Anzueto A, et al. Infectious Diseases Society of America/American Thoracic Society consensus guidelines on the management of community-acquired pneumonia in adults. Clin Infect Dis 2007; 44 Suppl 2:S27-72.

37. Quality of Care for Elderly Patients Hospitalized for Pneumonia in the United States, 2006 to 2010 (vol 174 , pg 1806, 2014). Jama Intern Med 2014; 174:1875-.

38. Wilson KC, Schunemann HJ. An Appraisal of the Evidence Underlying Performance Measures for Community-acquired Pneumonia. Am J Resp Crit Care 2011; 183:1454-62.

39. Battleman DS, Callahan M, Thaler HT. Rapid antibiotic delivery and appropriate antibiotic selection reduce length of hospital stay of patients with community-acquired pneumonia: link between quality of care and resource utilization. Arch Intern Med 2002; 162:682-8.

40. Dedier J, Singer DE, Chang Y, Moore M, Atlas SJ. Processes of care, illness severity, and outcomes in the management of community-acquired pneumonia at academic hospitals. Arch Intern Med 2001; 161:2099-104.

41. Arnold FW, Summersgill JT, Lajoie AS, et al. A worldwide perspective of atypical pathogens in community-acquired pneumonia. Am J Respir Crit Care Med 2007; 175:1086-93.

42. Lee JS, Nsa W, Hausmann LR, et al. Quality of care for elderly patients hospitalized for pneumonia in the United States, 2006 to 2010. JAMA Intern Med 2014; 174:1806-14.

43. Bahlis LF, Diogo LP, Kuchenbecker RS, Fuchs SC. Clinical, epidemiological, and etiological profile of 
inpatients with community-acquired pneumonia in a public hospital in the interior of Brazil. J Bras Pneumol 2018; 44:261-6.

44. Arnold FW, Summersgill JT, Lajoie AS, et al. A worldwide perspective of atypical pathogens in community-acquired pneumonia. Am J Resp Crit Care 2007; 175:1086-93.

45. Kalil AC, Metersky ML, Klompas M. Management of Adults With Hospital-acquired and Ventilator-associated Pneumonia: 2016 Clinical Practice Guidelines by the Infectious Diseases Society of America and the American Thoracic Society (vol 63, pg e61, 2016). Clin Infect Dis 2017; 65:2161-.

46. Mandell LA, Wunderink RG, Anzueto A, et al. Infectious Diseases Society of America/American Thoracic Society consensus guidelines on the management of community-acquired pneumonia in adults. Clin Infect Dis 2007; 44:S27-S72.

47. Bourcier JE, Paquet J, Seinger M, et al. Performance comparison of lung ultrasound and chest $x$-ray for the diagnosis of pneumonia in the ED. Am J Emerg Med 2014; 32:115-8.

48. Hu QJ, Shen YC, Jia LQ, et al. Diagnostic performance of lung ultrasound in the diagnosis of pneumonia: a bivariate meta-analysis. Int J Clin Exp Med 2014; 7:115-21.

49. Chavez MA, Shams N, Ellington LE, et al. Lung ultrasound for the diagnosis of pneumonia in adults: a systematic review and meta-analysis. Resp Res 2014; 15.

50. Ito A, Ishida T, Tokumasu H, et al. Prognostic factors in hospitalized community-acquired pneumonia: a retrospective study of a prospective observational cohort. Bmc Pulm Med 2017; 17.

51. Guidelines for the management, of adults with hospital-acquired, ventilator-associated, and healthcare-associated pneumonia. Am J Resp Crit Care 2005; 171:388-416.

52. Keramat F, Basir HRG, Abdoli E, Aghdam AS, Poorolajal J. Association of serum procalcitonin and $\mathrm{C}$-reactive protein levels with CURB-65 criteria among patients with community-acquired pneumonia. Int $\mathrm{J}$ Gen Med 2018; 11:217-23.

53. Que YA, Virgini V, Lozeron ED, et al. Low C-reactive protein values at admission predict mortality in patients with severe community-acquired pneumonia caused by Streptococcus pneumoniae that require intensive care management. Infection 2015; 43:193-9.

54. Khan F, Owens MB, Restrepo M, Povoa P, Martin-Loeches I. Tools for outcome prediction in patients with community acquired pneumonia. Expert Rev Clin Phar 2017; 10:201-11.

55. Horie M, Ugajin M, Suzuki M, et al. Diagnostic and prognostic value of procalcitonin in community-acquired pneumonia. Am J Med Sci 2012; 343:30-5.

56. Zhydkov A, Christ-Crain M, Thomann R, et al. Utility of procalcitonin, C-reactive protein and white blood cells alone and in combination for the prediction of clinical outcomes in community-acquired pneumonia. Clin Chem Lab Med 2015; 53:559-66.

57. Stolz D. Procalcitonin in Severe Community-Acquired Pneumonia Some Precision Medicine Ready for Prime Time. Chest 2016; 150:769-71.

58. Schuetz P, Briel M, Mueller B. Clinical Outcomes Associated With Procalcitonin Algorithms to Guide Antibiotic Therapy in Respiratory Tract Infections. Jama-J Am Med Assoc 2013; 309:717-8.

59. Corti C, Fally M, Fabricius-Bjerre A, et al. Point-of-care procalcitonin test to reduce antibiotic exposure in patients hospitalized with acute exacerbation of COPD. Int J Chron Obstruct Pulmon Dis 2016; 11:1381-9.

60. Ahalt V, Argon NT, Ziya S, Strickler J, Mehrotra A. Comparison of emergency department crowding scores: a discrete-event simulation approach. Health Care Manag Sci 2018; 21:144-55.

61. Morley C, Unwin M, Peterson GM, Stankovich J, Kinsman L. Emergency department crowding: A systematic review of causes, consequences and solutions. PLoS One 2018; 13:e0203316. 
62. Higginson I. Emergency department crowding. Emerg Med J 2012; 29:437-43.

63. Fee C, Weber EJ, Bacchetti P, Maak CA. Effect of emergency department crowding on pneumonia admission care components. Am J Manag Care 2011; 17:269-78.

64. Welker JA, Huston M, McCue JD. Antibiotic timing and errors in diagnosing pneumonia. Arch Intern Med 2008; 168:351-6.

65. Kanwar M, Brar N, Khatib R, Fakih MG. Misdiagnosis of community-acquired pneumonia and inappropriate utilization of antibiotics: side effects of the 4-h antibiotic administration rule. Chest 2007; 131:1865-9.

66. Tripp DG. Did an acute medical assessment unit improve the initial assessment and treatment of community acquired pneumonia--a retrospective audit. N Z Med J 2012; 125:60-7. 